\title{
A pandemia de 2020: prelúdio de um neoliberalismo renovado?
}

\author{
The pandemic of 2020: prelude of a renewed neoliberalism?
}

\section{Heitor Moreira Lurine Guimarães*}

\begin{abstract}
Resumo: 0 artigo aborda, a partir de uma perspectiva filosófica, a relação entre a pandemia gerada pela Covid-19 e a produção de subjetividades em um contexto global de neoliberalismo. 0 alastramento do coronavírus mundialmente, e a incapacidade dos sistemas de saúde em diversos países em atender a todos que necessitam, suscitou interpretações em que a presente crise de saúde mundial representaria um golpe fatal contra o modelo neoliberal vigente, de modo que tal episódio poderia significar um indício de enfraquecimento do capitalismo. Com base nos estudos sobre a governamentalidade neoliberal e a formação do saber médico realizados por Michel Foucault, pretende-se sustentar a hipótese de que, em verdade, a atual pandemia pode representar o surgimento de um neoliberalismo revigorado. Uma governamentalidade produtora de sujeitos docilizados, ao mesmo tempo, para a aceitação de mudanças bruscas em suas condições de vida e para a busca da produtividade sob a forma do empreendedor de si.
\end{abstract}

Palavras-chave: Neoliberalismo; Pandemia; Medo; Contágio; Subjetividade; Governamentalidade

Abstract: The article approaches, from a philosophical perspective, the relation between the pandemic caused by Covid-19 and the production of subjectivities in a global context of neoliberalism. The spreading of coronavirus worldwide and the incapacity of health systems throughout many countries to take care of all in need has given rise to interpretations that the global health crisis would mean a stinging blow to the neoliberal current model, so that such an episode could mean a sing of the decay of capitalism. Based on Michel Foucault's studies about governmentality and the formation of medical knowledge, we intend to argue for the hypothesis that, actually, the current pandemic may represent the rise of a revigorated neoliberalism. A governmentality which products subjects docilized, at the same time, to acceptance of abrupt changes in their life conditions and the seek for productivity in the form of enterprise of the self.

Keywords: Neoliberalism; Pandemic; Fear; Contagion; Subjectivity; Precarity; Governmentality

\section{A Covid-19 e o capitalismo neoliberal}

É seguro dizer que a pandemia gerada pelo Sars-Cov-2, mais conhecido como novo coronavírus, será um dos eventos mais marcantes da década, quiçá de todo o século XXI, embora tenha havido diversas outras pandemias significativas na história mundial recente. Sua relevância se explica não apenas pela necessidade de paralisação de uma parte considerável de alguns setores da economia em todos os continentes, mas também pela experiência social de redução do contato entre pessoas. Até o momento da conclusão deste trabalho, o número oficial de infectados no Brasil já era de aproximadamente oitenta mil pessoas, e no mundo, cerca de três milhões e duzentos mil, com altos crescimentos todos os dias.

A desordem em escala mundial desencadeada por esse acontecimento produziu algumas consequências notáveis. Na Itália, onde os efeitos do vírus já foram devastadores, o governo se comprometeu com o pagamento de oitenta por cento do valor dos salários na 
iniciativa privada. Na Espanha, houve a estatização de diversos hospitais em uma tentativa desesperada de controlar a demanda por atendimento médico. 0 próprio Brasil, historicamente relutante quanto à regulamentação de renda básica (universal ou não), encontrou-se compelido a adotá-la, por meio de um auxílio emergencial com duração, a princípio, de três meses.

Há quem acredite que tais fatos representariam um enfraquecimento do capitalismo neoliberal enquanto modo de produção, dado que a pandemia teria mostrado o quanto essa forma de organização social depende da exploração do trabalho e da concentração de renda para se perpetuar. Slavoj Zizek foi um dos que se posicionaram nesse sentido, ao afirmar que "talvez outro vírus ideológico, muito mais benéfico, se espalhe e nos contagie: o vírus do pensamento em termos de uma sociedade alternativa, uma sociedade para além do Estadonação, uma sociedade que se atualiza sob a forma de solidariedade e cooperação global"1. Semelhantemente, David Harvey defende que a conjuntura econômica, a julgar pela maneira como está sendo afetada pela pandemia, apresentará níveis de desemprego e queda do consumo que só poderão ser sanados por meio de uma socialização na economia ${ }^{2}$. Isso implicaria, em síntese, que até mesmo as nações em que a austeridade fiscal se apresenta em suas formas mais intensas estariam obrigadas a implementar medidas francamente contrárias à agenda neoliberal.

No que se segue, o artigo pretende fazer um contraponto a tais perspectivas, no sentido de mostrar, ainda que sucintamente, a existência de um potencial de que as consequências da Covid-19 sejam exatamente o recrudescimento do neoliberalismo enquanto forma de gestão social e de formação da subjetividade, tomando como base o pensamento de Michel Foucault. Para tanto, é interessante começar analisando brevemente um dos textos mais significativos do autor no que diz respeito ao controle exercido por meio da medicina, intitulado " $O$ Nascimento da Medicina Social", e posteriormente editado como quinto capítulo da "Microfísica do Poder". Nesse ensaio, Foucault explica que houve três paradigmas diferentes que levaram à constituição da medicina enquanto uma técnica de monitoração que se aplica não sobre este ou aquele indivíduo isolado, mas antes sobre uma coletividade inteira.

0 primeiro foi o que se desenvolveu na região correspondente à atual Alemanha, ao qual o autor chama de "medicina de Estado". No século XVIII, quando a Alemanha não existia como país unificado, a competição entre cada um dos reinos ali existentes gerou a necessidade de que cada um produzisse informações sobre as condições de vida em que se encontrava sua respectiva população, de modo que este conhecimento forneceria um parâmetro de comparação econômico-mercantil para com os reinos vizinhos. Consequentemente, os dados assim obtidos seriam aplicados na criação de estratégias de concorrência mais precisas e eficazes, que possibilitasse a cada reino melhorar a situação de sua balança comercial, aumentar o contingente de trabalhadores produtivos, dentre outras ações. Para tanto, os Estados desenvolveram programas institucionais de formação de médicos, com o duplo objetivo de manter um controle rigoroso de quem poderia exercer a profissão e de garantir que, quem quer o fizesse, possuísse sempre um mesmo conjunto de competências préestabelecidas. Pela primeira vez na história criou-se um sistema de formação e capacitação de médicos de maneira uniforme e regular, de modo a fazer com que as técnicas e os procedimentos empregados fossem sempre os mesmos e obedecessem a um mesmo padrão definido pelo Estado 3 .

O segundo modelo, produzido na França mais ou menos no mesmo período, teve como fator motivador a gestão da propagação de doenças nos recentemente formados centros urbanos. A estratégia empregada neste caso não foi, porém, a produção de profissionais

\footnotetext{
1 ZIZEK, Um Golpe como de "Kill Bill" no Capitalismo, p. 43.

${ }^{2}$ HARVEY, Política Anticapitalista em Tempos de Covid-19, p. 20.

${ }^{3}$ FOUCAULT, Microfísica do Poder, p. 83.
} 
normalizados, e sim a manipulação do espaço físico ${ }^{4}$. Tratava-se, pois, de gerenciar a propagação de doenças pela disposição das habitações, pela criação de canais de fluxo de ar e pelo gerenciamento do fluxo de indivíduos por um mesmo local, através de técnicas arquitetônicas. 0 reflexo prático dessa modalidade de medicina social ficou marcado na produção do espaço urbano tipicamente associado à engenharia francesa, que é bem exemplificado pelo modo de construção de avenidas, a distribuição estratégica de poços ao longo dos bairros e os sistemas de drenagem de água das ruas. Dessa maneira, na medicina urbana francesa, é a cidade como um todo que é medicalizada, ou seja, convertida, em sua totalidade, em um dispositivo de controle da saúde.

0 terceiro e último paradigma foi o que se estabeleceu na Inglaterra tão logo se precipitaram as consequências da Revolução Industrial, especialmente o surgimento de massas de trabalhadores pauperizados nas periferias, ambiente propício para a disseminação de epidemias. A resposta dada a tais novas circunstâncias pelo Estado inglês se deu pelo desenvolvimento de técnicas de medicina preventiva, com ênfase na vacinação e no esquadrinhamento das estatísticas de mortes e contágios em cada bairro. Essas estratégias tinham como objetivo, de um lado, impedir que a classe trabalhadora fosse atingida a ponto de prejudicar os padrões de produtividade de mercadorias da economia industrial e, do outro, evitar as epidemias chegassem aos membros das classes mais altas ${ }^{5}$.

A partir dessa caracterização, é possível observar que a prática médica atualmente exercida na pandemia da Covid-19 possui uma normatividade informada, simultaneamente, por elementos dos três paradigmas. Com efeito, ela tem como ideal o estabelecimento de um mesmo conjunto de procedimentos para lidar com a doença, inclusive a nível internacional, sob a égide da Organização Mundial da Saúde como instituição normalizadora. Além disso, as medidas de contenção adotadas pela maior parte dos países apresentam um forte apelo ao controle da circulação não somente de bens e mercadorias, mas principalmente da presença de pessoas em espaços públicos. Finalmente, é impossível negar que a manutenção da economia e a preservação do contingente de pessoas saudáveis economicamente ativas seja, para todos os Estados, um aspecto central da contenção do novo coronavírus, justamente por causa das recessões que esse acontecimento provavelmente desencadeará.

Até o presente momento, parece haver pelo menos dois tipos de estratégias empregadas a nível estatal, no que se refere à contenção da propagação da Covid-19. Uma delas, que pode ser observada de forma mais evidente em países como Espanha e Itália, aposta na maximização do confinamento doméstico e nas restrições de deslocamento de pessoas, agora passível, inclusive, de sanção pecuniária, ao mesmo tempo em que se procura isolar possíveis infectados pelo vírus das demais pessoas a todo custo. A outra estratégia, vigente, por exemplo, no Japão, em Singapura e na própria China, tem como modus operandi principal a monitoração eletrônica da população por meio do uso de dados móveis e do rastreio a partir de smartphones. Assim, o Estado utiliza programas que possibilitam em tempo real o deslocamento de pessoas ao longo de toda a cidade, e aplicar as sanções cabíveis com precisão e rapidez, quando necessário.

Não é difícil perceber como ambas as estratégias descritas apelam para tentativas de controle disciplinar dos corpos face à doença ${ }^{6}$. A primeira, ao que tudo indica, não demonstra diferenças muito significativas com os procedimentos de isolamento criados pela então nascente medicina social no século XVIII, para lidar com a peste bubônica que se espalhou pela Europa, conforme a análise de Foucault ${ }^{7}$. Obviamente, a tecnologia atualmente existente potencializa os efeitos de tais técnicas de confinamento, mas não alteram substancialmente seus métodos, nem os propósitos que pretendem alcançar. Quanto a estratégia dos países

\footnotetext{
4 FOUCAULT, Microfísica do Poder, p. 90.

${ }^{5}$ FOUCAULT, Microfísica do Poder, p. 96.

${ }^{6}$ FOUCAULT, Vigiar e punir, p. 110.

7 FOUCAULT, Vigiar e Punir, p. 125.
} 
asiáticos mencionados, se há uma distinção substancial na forma de lidar com a pandemia por parte deles, provavelmente consiste no fato de que lá se atingiu um tal nível de aproveitamento dos recursos tecnológicos a ponto de a vigilância sanitária prescindir que os indivíduos se encontrem no interior de estruturas arquitetônicas de grande porte para serem vigiados.

À luz dessa consideração, parece já haver aqui uma razão preliminar para colocar em suspenso o diagnóstico positivo exemplificado pelas referidas posições de Zizek e Harvey. Pois, como diz claramente Foucault, "foi no biológico, no somático, no corporal que, antes de tudo, investiu a sociedade capitalista" 8 . Nesse sentido, se a medicina social foi historicamente pedra angular da constituição e manutenção do capitalismo, e se há continuidades históricas entre aquelas práticas médicas e as práticas atualmente observadas por ocasião da pandemia, seria difícil afirmar que a prática médica suscitada pelo coronavírus não é ela própria uma forma de normalização minuciosa sobre os corpos, igualmente a serviço da preservação do modo de produção capitalista.

Essas problematizações iniciais, com relação a diagnósticos positivos a respeito da atual situação de emergência em que se encontra o mundo, levantam outras questões. Diante do tipo de medidas de urgência adotas pelos Estados, como as citadas no começo deste artigo, caberia perguntar qual a sua real natureza: se elas são mudanças que acenam para um novo contexto institucional e social mais livre pós-pandemia ou se poderiam se reverter em partes de estratégias que futuramente permitiriam a retomada (ou mesmo a intensificação) de certos aspectos, como será explicitado a seguir, do status quo anterior. Ou seja, o estado de coisas pensado como excepcional em tempos de pandemia, poderia ser adotado como regra. Em última instância o que está em jogo é se a crise produzida pela pandemia pode ser interpretada como a passagem para uma condição que reforça ideais de solidariedade e de cooperação, ou não. Na medida em que este ponto diz respeito à maneira como o comportamento dos indivíduos é controlado, é indispensável recorrer às análises foucaultianas sobre a governamentalidade neoliberal.

\section{O neoliberalismo em Foucault}

0 tema da governamentalidade surge na obra de Foucault por ocasião de seus estudos sobre o biopoder, isto é, o poder que se exerce sobre os fenômenos biológicos com natalidade, mortalidade, envelhecimento, dentre outros. Foucault descobriu que todo esquema de normalização em forma de biopoder é exercitado sempre por meio de uma certa arte de governar os indivíduos. É importante observar, a esse respeito, que a palavra governar, em Foucault, assume sentido diverso do usual, na medida em que significa toda forma de controlar e conduzir as condutas de um grupo de indivíduos. Em síntese, governar significa manipular um estado de coisas a fim de que um grupo de indivíduos desenvolva certos padrões de comportamento, modos de vida, preferências, habilidades, ou seja, uma forma abrangente de formação da sua subjetividade.

Esse ponto leva diretamente ao neoliberalismo pois, para Foucault, a racionalidade neoliberal constitui justamente o tipo de governamentalidade vigente pelo menos desde a segunda metade do século XX. E quais são os traços principais do sujeito produzido pelo neoliberalismo? Talvez sua característica mais notória seja que este sujeito apresenta uma atitude em relação a si mesmo e ao mundo que é bem sintetizada pela canônica expressão "empresário de si mesmo" 9 . Significa dizer que o sujeito neoliberal é disciplinado para lidar com a vida, com o tempo e com as suas relações pessoais de uma maneira que consiste em constantemente definir metas e objetivos, e estratégias e tácticas que levem à sua obtenção.

${ }^{8}$ FOUCAULT, Microfísica do Poder, p. 80.

${ }^{9}$ FOUCAULT, Nascimento da biopolítica, p. 311. 
Trata-se de tratar a si próprio como uma empresa, que precisa instrumentalizar os recursos que possui à sua disposição, mobilizando-os como meios de realização dos objetivos que define para si.

Para a presente discussão, há duas consequências especialmente importantes do modo de subjetivação neoliberal. A primeira é o que Dardot e Laval, que endossam o diagnóstico foucaultiano, chamam de "individualização do destino" 10 . Consiste no fato de que, como o neoliberalismo gera no indivíduo uma perspectiva de mundo autocentrada, todas as experiências de dificuldade, de insucesso e de fracasso nas aspirações pessoais são experienciadas como consequências da incompetência de cada pessoa de ser um bom gestor de si mesmo, nunca como algo provocado por uma conjuntura econômica. Essa é a posição defendida por Milton Friedman, expoente do neoliberalismo da Escola de Chicago. Segundo Friedman, a única forma de tornar o ser humano plenamente livre é criando condições para que ele seja obrigado a exercitar sua capacidade de cálculo racional na elaboração de planos para si ${ }^{11}$. Contudo, o resultado imediato desse processo, segundo Dardo e Laval, é o embotamento da percepção da conexão entre fatos ocorridos no âmbito da vida pessoal e os grandes esquema de normalização mais amplos vigentes na sociedade como um todo.

A segunda consequência, intimamente conectada com a primeira, é que o sujeito neoliberal é marcado por uma busca por reinventar a si mesmo constantemente. Diante de percalços e acontecimentos de caráter conjuntural que estão para além do controle de cada pessoa individualmente (como crises econômicas), o neoliberalismo insufla uma práxis na qual cada indivíduo aprende que compete a ele próprio, por uma escolha racional que leva em consideração os resultados benéficos e maléficos de cada ação, pavimentar seu próprio caminho para a prosperidade. Nessa lógica de subjetivação, cabe ao indivíduo, gerente de sua própria vida e existência, a busca de estratégias ou planos de ação que lhe permitam a superação das situações adversas que se colocam diante dele. Posto que o indivíduo é treinado para se comportar como uma empresa de si, a fiscalização e administração dos riscos a cada um de seus projetos também são, no interior dessa governamentalidade, de sua inteira responsabilidade.

$\mathrm{Na}$ visão neoliberal, contudo, a responsabilização do indivíduo por si mesmo é entendida não como precarização das suas condições de vida, mas sim como liberdade e emancipação ${ }^{12}$. Provavelmente a defesa mais clara dessa perspectiva encontra-se em Friedrich Hayek, expoente do neoliberalismo austríaco, para quem todo tipo de assistencialismo estatal é a antessala do totalitarismo, na medida em que ensina os indivíduos a amar o Estado e a se tornarem dependentes dos benefícios governamentais ${ }^{13}$. É exatamente essa leitura histórica e econômica -que traz consigo também uma visão do ser humano como um ser que faz escolhas sempre com vista à maximização dos benefícios- utilizada por Hayek para fazer uma defesa do valor intrínseco do mercado e da importância de estimular cada indivíduo à concorrência ${ }^{14}$.

Como apontam Dardot e Laval, dentre as principais manifestações dos dois fenômenos apontados supra, está a proliferação de práticas e serviços como a accountabilty pessoal e o famigerado coaching. Este se baseia no desenvolvimento de habilidades estratégicas com vista à consecução de certo resultado determinado previamente; aquela, no controle rigoroso dos desempenhos e seus padrões de crescimento e decrescimento. Cada uma à sua maneira, ambas as práticas são representativas da maneira como a racionalidade prática tipicamente empresarial é paulatinamente transplantada para a esfera da vida pessoal e passa a reger até as dimensões mais banais do cotidiano.

\footnotetext{
10 DARDOT; LAVAL, A nova razão do mundo, p. 349.

11 FRIEDMAN, Capitalism and freedom, p. 121.

12 FRIEDMAN, Capitalism and freedom, p. 8.

13 HAYEK, $O$ caminho da servidão, p. 104.

${ }^{14}$ HAYEK, $O$ caminho da servidão, p. 137.
} 
As considerações feitas até aqui poderiam suscitar objeções. Com efeito, não seria o coronavírus justamente o acontecimento que prova como essa arte de governar é insustentável? A dificuldade no acesso a serviços de saúde, bem como os abalos econômicos decorrentes da necessidade de distanciamento social não seriam exatamente a prova de que uma racionalidade individualizante pode facilmente sucumbir perante mudanças drásticas nas circunstâncias, como diz Harvey? Não seria este um sinal claro da urgência por cooperação mútua e solidariedade, como diz Zizek?

Pautado nos traços do neoliberalismo há pouco explicitados, o restante deste artigo tentará esboçar uma resposta a tais objeções. No atual estágio em que a pandemia se encontra, contudo, é preciso reconhecer que ainda não há informações e bibliografia o bastante para fazer afirmações de caráter peremptório. Por essa razão, os argumentos que se seguem pretendem apenas fazer alguns apontamentos para quais pontos poderiam ser explorados pela governamentalidade neoliberal de modo não só a evitar seu enfraquecimento, mas, principalmente, a torná-la ainda mais poderosa.

Há um esclarecimento importante a fazer. 0 fato de que estejamos assistindo à posturas mais ativas por parte dos governos de diversos países, como os mencionados no início, nada significa, a princípio, em termos de arrefecimento do neoliberalismo. Provavelmente, uma das lições mais relevantes encontradas nos estudos de Foucault e dos que o seguem sobre a arte de governar neoliberal é que a associação comumente entre ela e um progressivo afastamento do Estado da gestão da sociedade não poderia estar mais distante da realidade atual. A genealogia foucaultiana é bem clara em mostrar como a ascensão do neoliberalismo depende da disseminação de uma ética da concorrência elevada à sua máxima potência, o que por sua vez só se pôde realizar, ao longo do século XX, por meio de significativas intervenções estatais.

Em verdade, um exame cuidadoso dos principais teóricos neoliberais mostra que nelas não há uma rejeição pura simples à atuação do Estado, mas sim às intervenções restritivas da liberdade econômica. Hayek, por exemplo, embora pense que o mercado faz parte de uma ordem espontânea do agir humano (cosmos), acredita que ela só pode florescer quando o Estado usa seu poder para criar suas condições de possibilidade, remover obstáculos e facilitar seu desenvolvimento ${ }^{15}$. Então, há pelo menos um tipo de intervenção endossada pelo neoliberalismo: aquela que abre espaço para o mercado. Assim, uma intervenção motivada por um fator estranho ao ambiente mercadológico, como o coronavírus, poderia ser aceita pela visão neoliberal, desde que se paute em suas premissas fundamentais.

Isso chama atenção para um outro aspecto crucial da problemática. À medida que avançava em suas pesquisas sobre a governamentalidade, Foucault veio a descobrir que a arte de governar os seres humanos, em qualquer das suas manifestações, não significa a eliminação da sua liberdade, tampouco a simples ocultação da realidade tal como ela é, como pressuposto no conceito marxista de alienação. Pelo contrário, governar exige, acima de tudo, liberdade. Ou melhor, exige uma gestão das formas de exercício da liberdade. Na esteira do raciocínio que se vinha desenvolvendo até aqui, pode-se afirmar que governar consiste, sobretudo, em fazer o sujeito assenhorear-se de si mesmo de uma certa maneira, isto é, fazer o sujeito apoderar-se de sua relação consigo mesmo, de seu corpo e de sua vida de um jeito específico. Em síntese, toda governamentalidade- mas especialmente, como dito, a neoliberalnecessita de tornar o indivíduo um agente ativo na produção da sua própria subjetividade.

Assim, é seguro afirmar que o tipo de conduta produzida pela pandemia de coronavírus resulta em uma subjetividade particularmente marcada pelo medo do contágio. Em todas as maneiras de se conduzir ditadas pela necessidade de prevenção da Covid-19, está presente um ideal normativo que procura orientar o olhar e a percepção de cada um dos indivíduos nos seguintes termos. Enxergar em si e nos outros potenciais vetores de contágio,

${ }^{15}$ HAYEK, $O$ caminho da servidão, p. 57-60. 
o que deverá servir como parâmetro em cada uma de suas interações interpessoais. Prestar atenção, constantemente, em si, em seu estado físico e nos sinais que seu corpo apresenta. Aprender a tomar a si próprio como um ente que necessita de cuidado e de proteção contra ameaças biológicas externas, que podem advir de praticamente qualquer lugar e qualquer pessoa. Finalmente, levar em consideração, em cada um de seus atos, o risco de transmissão que deles pode advir.

A ideia de que o medo de algo pode funcionar como elemento central na e formação e organização de uma subjetividade não é de modo algum alheia ao pensamento de Foucault. Em "Do Governo dos Vivos", Foucault afirma explicitamente que o medo foi crucial na definição da relação do cristão com a sua própria existência a partir do pensamento de Tertuliano, e do surgimento da catequese enquanto instituto eclesiástico. "O cristão, quando se prepara para o batismo, e uma vez batizado, não deve nunca abandonar o medo"16. Obviamente, naquele caso o medo era dirigido não a uma ameaça biológica, mas à própria crença de que, a partir do pecado original, a alma humana teria sido impregnada de elementos oriundos do Maligno, que a todo momento ameaçam se manifestar sob a forma de tentações.

É o medo em relação a essas manifestações do elemento maligno presente em cada um, conclui Foucault, aquilo que leva o sujeito cristão, do século III em diante, a viver sob um regime de autovigilância e exame de consciência. Medo este explicitamente insuflado pelas autoridades eclesiásticas. Com base nessa análise histórica, é seguro afirmar que a reconfiguração do modo de funcionamento da sociedade como um todo em função do perigo do coronavírus, como ocorreu a nível global, tem como um de seus efeitos a definição de uma nova forma de subjetividade também modelada com base no medo. Nesse caso, porém, o medo de uma ameaça biológica. E, como em toda situação em que se pode verificar o exercício de qualquer forma de poder, a produção de tal subjetividade depende diretamente de certos procedimentos de produção da verdade. No presente contexto, esse papel de produção da verdade é desempenhado exatamente pelo conhecimento científico gerado a partir do método experimental, e disseminado por médicos, gestores públicos, dentre outros agentes sociais.

0 que há de mais interessante nessa subjetividade, que governa a si mesma orientada pelo medo do contágio, é o seguinte. Posto que ela leva a práticas de autorrestrição, de autolimitação, ela cria condições propícias para a facilitar a flexibilização da sua liberdade, em sentido político-jurídico. Quer dizer, um dos efeitos do surgimento de uma forma de autogoverno baseado no contágio, além da evidente propensão ao acirramento do racismo e da xenofobia, é que os indivíduos passem, progressivamente, a considerar como legítimas mudanças abruptas em suas condições de vida que alteram radicalmente a possibilidade do exercício de sua liberdade. Do ponto de vista da relação saber-poder estabelecida por Foucault, a proliferação do saber médico-sanitário a respeito do contágio suscita novas relações de poder- seja entre indivíduos, seja entre o Estado e os indivíduos- as quais fazem emergir um sujeito que não só aceita, como também considera corretas, as restrições que se lhe colocam.

É, também, precisamente este ponto que estabelece o vínculo entre a presente reflexão e a temática do possível recrudescimento do neoliberalismo pós-pandemia. Retomando a observação feita anteriormente, foi dito que um dos traços da governamentalidade neoliberal é converter o risco em um objeto de controle pessoal. Nesse contexto, o que o caos social decorrente da Covid-19 faz é justamente adicionar o risco do contágio ao rol dos ricos que cada pessoa, dentro da ordem neoliberal, precisa administrar em sua vida. Nesse momento, porém, a inserção do medo do contágio como elemento integrante da relação do sujeito consigo mesmo torna-o progressivamente mais tolerante perante formas cada vez mais severas de cerceamento de suas garantias básicas e do exercício de suas relações sociais. Isto é, faz com que circunstâncias cada vez menos livres pareçam-lhe mais admissíveis, mais

16 FOUCAULT, Do governo dos vivos, p. 116. 
justificadas. Ocorre que é justamente essa subjetividade maleável e pronta para sofrer mudanças repentinas a que mais favorece uma arte de governar neoliberal.

Nessa perspectiva, nada poderia configurar um solo mais fértil para o amadurecimento do neoliberalismo do que uma massa de indivíduos já resignados e dispostos a aceitar que boa parte de suas possibilidades de escolha e ação normais sejam suspensas. Ou seja, uma coletividade previamente preparada para viver prolongados períodos de privação daquilo que em outros contextos seria indispensável e insubstituível, sempre que isso parecer justificado com base neste ou naquele regime de produção da verdade, seja ele médico-sanitário ou de outra natureza. Sob essa ótica, não seria absurdo imaginar, pouco após o momento em que a Covid-19 esteja controlada, o ressurgimento, com força total, de políticas de austeridades fiscal, justificadas com base em situações de recessão provenientes dos esforços que estão sendo empreendidos pelos Estados no momento presente. Contudo, tal cenário nada mais seria do que a transição de uma situação de precariedade causada por uma ameaça biológica para uma situação de precariedade socialmente induzida por decisões institucionais. A diferença é que, a partir da excepcionalidade extrema vivenciada durante a pandemia, a aceitabilidade do neoliberalismo revigorado seria plausivelmente mais fácil, ou encontraria menos resistência em um corpo social já docilizado.

Se, dada a lógica da concorrência generalizada, a solidariedade social e resistência coletiva já são duas das maiores vítimas da corrosão neoliberal, o olhar autocentrado e orientado para a procura de eventuais ameaças à saúde por todos os lugares, que emerge a partir da subjetivação na situação pandêmica, representa o último passo na construção do sujeito dócil de que o neoliberalismo depende para levar adiante seus esquemas de normalização sob a forma da empresa. Pois a experiência da pandemia leva à uma rotina de obediência e cuidado autointeressado do bem-estar individual que, em última instância, é perfeita para a aceitação passiva da relativização de direitos e garantias fundamentais, de que o neoliberalismo, como forma de racionalidade, tanto depende.

A docilização de que se fala aqui, contudo, não é idêntica àquela que havia sido identificada por Foucault por ocasião de suas análises a respeito do surgimento de poder disciplinar. Em certo sentido, tal como naquele contexto, também se trata da produção de um tipo de "corpo que pode ser submetido, que pode ser utilizado, que pode ser transformado e aperfeiçoado"17. Contudo, há uma diferença. Se, naquele contexto, tornar um corpo dócil significava treiná-lo e domesticá-lo para a execução de tarefas produtivas, no presente contexto, docilizar implica, acima de tudo, produzir corpos capazes de aceitarem (e mesmo de desejarem) sua própria subordinação perante instituições que se apresentam como se seu único propósito fosse a proteção do bem-estar coletivo. Isto é, corpos que, diante de uma situação que lhes seja apresentada como emergencial, não demonstram pouca ou nenhuma insurgência quanto àquilo que ameaça privá-los de seus direitos e garantias.

É importante não confundir essa última afirmação com uma que têm sido feita por aqueles que se opõem ao distanciamento social, a saber, de que essa medida consiste em uma suspensão arbitrária das liberdades de locomoção e reunião. Nota-se, pelo menos no contexto do Brasil, que os adeptos desse posicionamento amiúde também acreditam que o fim do distanciamento é um imperativo em função dos efeitos nefastos que podem advir da paralização prolongada de vários setores da economia. 0 próprio uso de um argumento dessa natureza, pautado em um cálculo de custo-benefício em termos monetários, por si mesmo, denuncia que se trata de um pensamento claramente neoliberal. Inclusive, o fato de que um posicionamento como esse seja defendido por figuras públicas e donos de grandes em presas no Brasil, nas atuais circunstâncias, é uma das mais importantes evidências de como a racionalidade neoliberal não só não tem escrúpulos em relativizar a vida humana, mas também a insere em seus cálculos como apenas mais uma variável a ser administrada. A

17 FOUCAULT, Vigiar e Punir, p. 126. 
constatação de tal fato corrobora a perspectiva foucaultiana utilizada como referência neste artigo.

Nesse sentido, ao se invocar a noção de docilidade mobilizada por Foucault, tem-se em vista uma questão inteiramente diferente de eventuais "prejuízos econômicos": o potencial que o momento da Covid-19 tem de ser usado estrategicamente como a preparação do terreno para uma versão ainda mais intensa do neoliberalismo que existiu até o presente. 0 exemplo mais significativo desse fenômeno talvez seja o daquele contingente de trabalhadores assalariados que têm possibilidade de permanecer em distanciamento social. Por um lado, a casa se torna o novo espaço de confinamento, aquele ambiente que teoricamente está sob poder do indivíduo o qual ele não pode deixar. Por outro lado, como demonstra Foucault, as manifestações do poder jamais resumem a meros efeitos de restrição ou repressão.

Para esses trabalhadores, o lar também é convertido em ambiente de maximização de produtividade, em que ou se exige o cumprimento das mesmas metas (mas em condições de trabalho anormais), ou, especialmente no Brasil, recorre-se a uma relativização das metas sob condição de suspensão da remuneração normal, a exemplo da redução da jornada de trabalho, concomitante com a redução salarial, sem a possibilidade de resistência. Tudo isso com a chancela legal, no caso do Brasil, por meio de Medidas Provisórias, dentre as quais pode-se citar a Medida Provisória 936/20, cujo teor estabelece a possibilidade de suspensão das jornadas de trabalho e remunerações por até noventa dias.

No primeiro caso, que ocorre por meio do home office, do ensino remoto ou qualquer modalidade de teletrabalho, o indivíduo em questão está obrigado a se autogovernar racionalmente por meio de um difícil equilíbrio entre a manutenção de seus rendimentos usuais e os novos riscos decorrentes da Covid-19. No segundo caso, uma vez em privação, ainda que parcial, dos meios de subsistência cotidianos, a única solução é exercitar o mesmo tipo de atividade de empresa de si que o neoliberalismo prescreve como a solução por excelência para situações de dificuldade financeira, que se traduzem mormente na forma de serviços por aplicativo. Em ambos as situações, o aumento da precariedade, potencializado pelas medidas de isolamento, é evidente.

Quanto àqueles cujos serviços não podem prescindir do seu deslocamento, resta a inevitabilidade de se expor ao risco, consequência onipresente de toda manifestação da biopolítica, condensada na fórmula foucaultiana de "fazer viver e deixar morrer"18. 0 fato de que uma parte da população precisa permanecer relativamente mais vulnerável ao perigo da Covid-19- como aqueles que atuam nos ramos da saúde e da segurança pública- é algo que já está de certa forma inscrito em todo esquema de normalização que pretende administrar de forma abrangente os fenômenos biológicos relacionados à vida humana. Pois, para proteger e fomentar as vidas de alguns, é necessário que as vidas de outros sejam entregues à possibilidade de perecer. Isso é verdadeiro tanto quanto a paradigmas de governamentalidade históricos como o colonialismo ${ }^{19}$ quanto a programas de ação de saúde em massa, como o que ora é implementado para lidar com a Covid-19.

Portanto, o regime de distanciamento social, considerado isoladamente, nada tem de incompatível com a normatividade neoliberal do sujeito empresário de si. No mesmo sentido, a ideia de que essa circunstância é propícia para o florescimento do sentimento de solidariedade e ajuda mútua, como parecem crer Zizek e Harvey, revela-se precipitada, ou mesmo implausível. Dadas as possibilidades de trabalho remoto, é mais acertado dizer que o lar é convertido no ambiente ideal para se produzir, cujo efeito não é senão a inevitabilidade do exercício da ética de ser empresário de si, elevada à sua máxima potência.

${ }^{18}$ FOUCAULT, Em defesa da sociedade, p. 202.

${ }^{19}$ MBEMBE, Necropolítica, p. 27. 


\section{Conclusão}

Finalmente, é importante fazer algumas últimas considerações. No mesmo espírito da genealogia do poder foucaultiana, o estudo dos aspectos em que a Covid-19 oferece ao neoliberalismo oportunidades de recrudescimento não equivale a sustentar uma posição de negação generalizada da problemática. Tampouco pretende endossar atitudes de desobediência anárquica ou irracional às recomendações feitas por instituições de saúde. Em vez disso, o que se procurou fazer foi lançar luz, ainda que de forma breve, sobre aspectos que perspectivas excessivamente positivas parecem incapazes de captar. Em última instância, como toda genealogia, um estudo dessa natureza tem como finalidade cultivar a capacidade de pensar criticamente sobre o processo de subjetivação em que uma civilização se encontra enredada.

Em se tratando da pandemia vivenciada pelo mundo, observar as intervenções sanitárias de uma perspectiva genealógica visa a não permitir que consequências que ultrapassam a proteção da saúde se concretizem de forma silente. Expostos tais aspectos problemáticos a respeito do presente status quo, os problemas sobre como se deve agir, quais as melhores e mais prudentes formas de resistência, e como se pode evitar a produção de efeitos nefastos, com os mencionados no trabalho, constituem questões à parte, cujo exame demandaria análise de uma miríade de fatores, o que seria o objeto para uma outra investigação.

\section{Referências}

MBEMBE, Achille. Necropolítica. 3. ed. São Paulo: N-1 Edições, 2018.

DARDOT, Pierre; LAVAL, Christian. A nova razão do mundo: ensaio sobre a sociedade neoliberal. Trad. Mariana Echalar. São Paulo: Boitempo, 2016.

FRIEDMAN, Milton. Capitalism and Freedom. 3. ed. Chicago: University of Chicago Press, 2002.

FOUCAULT, Michel. Em defesa da sociedade: curso no Collège de France (1975-1976). Trad. Maria Ermantina de Almeida Prado Galvão. 2. ed. São Paulo: Martins Fontes, 2010.

FOUCAULT, Michel. Vigiar e punir: história da violência nas prisões. Trad. Lígia M. Pondé Vassalo. 14. ed. Petrópolis, RJ: Vozes, 1996.

FOUCAULT, Michel. Microfísica do poder. Organização e tradução de Roberto Machado. Rio de Janeiro: Edições Graal, 1979.

FOUCAULT, Michel. Do governo dos vivos: curso no Collège de France (1979-1980). Trad. Eduardo Brandão. São Paulo: Martins Fontes, 2014.

FOUCAULT, Michel. Nascimento da biopolítica: curso dado no Collège de France (1978-1979). Trad. Eduardo Brandão. São Paulo: Martins Fontes, 2008.

HARVEY, David, Política Anticapitalista em Tempos de Covid-19. In: DAVIS, Mike et al. Coronavírus e a luta de classes. Terra sem Amos: 2020.

HAYEK, Friedrich. O caminho da servidão. 6. ed. São Paulo: Instituto Ludwig von Mises, 2010.

ZIZEK, Slavoj, Um Golpe como de "Kill Bill" no Capitalismo. In: DAVIS, Mike et al. Coronavírus e a luta de classes. Terra sem Amos: 2020. 